\title{
Fertilization in the pig and horse
}

\author{
C. Polge \\ A.R.C. Institute of Animal Physiology, Animal Research Station, 307 Huntingdon Road, \\ Cambridge
}

Reproductive efficiency is one of the most important components in the economy of animal production and it is well recognized that it can be influenced by many factors affecting different areas of the reproductive process. Fertilization is just one of the essential links in the whole chain of reproductive events leading to the production of offspring, but it is the link most closely associated with the efficiency of breeding by means of artificial insemination. Different techniques used in A.I., especially those concerned with methods of insemination or with the dilution and storage of semen, can therefore best be assessed by their effects on fertilization and these aspects will be emphasized in the present paper.

Before considering some specific factors affecting fertilization in the pig and horse it is useful to review the general level of reproductive efficiency which is obtained under conditions of natural mating or A.I. in these two species. The two indicators for measuring reproductive efficiency in the pig (apart from the frequency of the production of offspring) are (1) farrowing rate, which is the proportion of animals farrowing after mating or insemination during one oestrous period, and (2) litter size, which is the number of live young born. Results from natural mating vary considerably from farm to farm and there is some controversy as to what should constitute the most appropriate sample to select. However, perhaps the best figures available in Britain at the present time are those obtained from herds recorded by the Meat and Livestock Commission. These give an average farrowing rate of $85 \%$ with a litter size of 11.0 (H. C. B. Reed, personal communication). Farms within this scheme are probably some of the best in the country. A.I. in pigs has been applied commercially in Britain for many years, but still only about $5 \%$ of the national herd is bred by this means although the service is used over a fairly broad spectrum of farms. The most recent results, again obtained from the Meat and Livestock Commission through their National A.I. service, give a farrowing rate of $76 \%$ with an average litter size of 10.2 from 6600 pigs inseminated during the first 6 months of 1977 (H. C. B. Reed, personal communication). These figures are from what is termed "the semen delivery service" whereby semen is supplied to farmers who then carry out the inseminations on their own farms. Some farmers using this service, principally those who do reasonably large numbers of inseminations per year, consistently achieve results higher than average. Nevertheless, it must be concluded that, A.I. at the present time is slightly less efficient than natural mating.

The reproductive efficiency of horses is often considered to be lower than that of other large domestic animals, but this opinion may be erroneous as it is influenced by a number of circumstances, not least of which is the tendency to try to breed mares earlier than the optimum time in the normal breeding season. In a survey of the reproductive efficiency of the Quarter-horse and Thoroughbred undertaken by Sullivan, Turner, Self, Gutteridge \& Bartlett (1975) in North America, $47 \%$ of mares were diagnosed pregnant 35-45 days after mating or insemination during one oestrous period and $40 \%$ foaled. The pregnancy and foaling rates were generally higher in the Quarter-horse than the Thoroughbred. A.I. is generally not used to any large extent in horse breeding and not at all in Thoroughbreds, but when it has been applied it has been shown that results at least as good as those of natural mating can be obtained (Pickett \& Voss, 1972). Nevertheless, because experiments with the horse have been on rather a small scale and optimal results are generally achieved only with fresh semen, a fair comparison cannot be drawn between this and A.I. in other species in which large-scale operations are involved.

An interpretation of these figures for reproductive efficiency in terms of the efficiency of fertilization can only be made if the extent of embryonic loss is known and this involves the examination of eggs shortly after mating or insemination. Few such studies have been done in the horse, but good 
data are available for the pig. Natural mating under optimal conditions, in which sows are served twice during oestrus, usually results in very high fertilization rates and examination of eggs shortly after mating shows that complete failure of fertilization occurs in only $5 \%$ of animals (Hancock, 1958; Thibault, 1959; Perry \& Rowlands, 1962). Therefore, if the average farrowing rate is $85 \%$, it can be assumed that in about $10 \%$ of the animals fertilization occurred, but the complete litter was lost during the course of gestation. Similarly, the proportion of ovulated eggs which are fertilized in individual animals is usually also very high and is $100 \%$ in most sows but embryonic losses may amount to $30-40 \%$ of the fertilized eggs (Perry, 1960) and the average litter size is therefore considerably below that of the ovulation rate. (For a review of embryonic and fetal losses in the pig, see Wrathall, 1971.) The reductions in farrowing rate and litter size obtained by A.I. as compared to natural mating probably represent a reduction in both the proportion of animals fertilized and in the proportion of eggs fertilized in individual animals.

The important influence of embryonic and fetal losses on reproductive efficiency must apply equally in the horse as in the pig. Fetal losses in the horse after the 2 nd month of gestation may be as high as $12 \%$ (Sullivan et al., 1975) and if early embryonic losses before that time are as great as those in the pig, the actual efficiency of fertilization in these two species may not be very much at variance.

Apart from intrinsic differences in fertility between males, the main factors influencing fertilization when semen is used for A.I. are those affecting the numbers of viable spermatozoa at the site of fertilization when the eggs are ovulated. We are therefore concerned with the transport of spermatozoa and their survival in the female reproductive tract, the time of ovulation during oestrus and the infiuence of storage methods on the viability and fertilizing capacity of spermatozoa.

\section{Sperm transport and survival}

Sperm transport in species with intrauterine deposition of semen, which includes the pig and horse, has been extensively reviewed by Hunter $(1973,1975 \mathrm{a}, \mathrm{b})$. Briefly, the large volume of semen which enters the uterus at the time of mating in the pig is distributed rapidly throughout the uterine horns (Mann, Polge \& Rowson, 1956) and this is facilitated by the contractile activity of the reproductive tract. Some studies have involved the recovery of spermatozoa and seminal fluid from different areas of the reproductive tract at various times after mating or insemination. However, a visual impression of fluid transport within the uterus has been obtained by 'inseminating' pigs during oestrus with a radio-opaque fluid and taking X-ray pictures of the excised tracts later (Plate 1). In contrast to the findings of similar experiments in the cow (Rowson, 1955), in which radio-opaque material was found within the oviducts shortly after its introduction into the uterus at oestrus, there is no bulk transport of fluids into the oviducts of pigs. The uterotubal junction and lower region of the isthmus act as a partial barrier to sperm transport, limiting and regulating the number of spermatozoa that enter the upper regions of the oviduct. Nevertheless, as in most other mammals (Austin, 1964), rapid transport of some spermatozoa to the site of fertilization can occur in the pig because a few have been found in the oviducts within $15-30 \mathrm{~min}$ of mating. A technique of post-coital isolation of the oviducts has been used to define the timing of entry of a population of spermatozoa into the oviducts (Hunter \& Hall, 1974a). In pigs mated shortly after the time of induced ovulation and in which the oviducts were separated from the uterine horns within $30 \mathrm{~min}$ of mating, it was found that sufficient spermatozoa were present within the oviducts to fertilize a proportion of the eggs. Rapid transport of spermatozoa to the oviducts may be advantageous in animals inseminated close to the time of ovulation, but of far more general importance is the fact that within a few hours of mating or insemination most of the spermatozoa and seminal fluid has been eliminated from the uterus and only a relatively small number of spermatozoa persist in the region of the uterotubal junction and lower part of the isthmus. This region has been termed the "sperm reservoir" (du Mesnil du Buisson \& Dauzier, 1955), and it assumes a dual role, first to regulate the number of spermatozoa entering the oviduct and second to act as a depot to ensure that spermatozoa will be present at the site of fertilization throughout oestrus and until the eggs are ovulated. 
Studies on the distribution of spermatozoa within the reproductive tracts of sows at various intervals after insemination (Rigby, 1964, 1966) confirmed the fact that only a very small proportion of the total number of spermatozoa inseminated could be recovered within a few hours of insemination, but it was established that the number of spermatozoa in the oviduct over a period of time following insemination was directly related to the number of spermatozoa surviving in the region of the uterotubal junction and lower isthmus. In sows inseminated $24 \mathrm{~h}$ after the onset of oestrus, the number of spermatozoa persisting in the reservoir remained relatively unchanged for 6-24 $\mathrm{h}$ and then decreased and disappeared over the next $48 \mathrm{~h}$.

Sperm transport and distribution in the horse following insemination appears to be similar to that in the pig (Parker, Sullivan \& First, 1975). However, the sites of sperm storage remain to be determined although evidence for extreme longevity of spermatozoa within the tract is provided by the fact that conception has been recorded in mares inseminated 5 or 6 days before ovulation (Day, 1942).

In animals mated or inseminated at various times before ovulation, fertilization will obviously be determined by the number of spermatozoa surviving in the sperm reservoir. The time of ovulation in pigs has been estimated to be $34 \pm 6 \mathrm{~h}$ after the onset of oestrus, although experimentally it can be controlled quite accurately by the injection of hCG during late pro-oestrus, and ovulation then occurs 40-42 h after injection (Dziuk, Polge \& Rowson, 1964; Hunter, 1967a). The mean volume of semen in a normal ejaculate of a boar is in the region of $250 \mathrm{ml}$ with a sperm concentration of $1-2 \times 10^{8}$ per $\mathrm{ml}$ (Polge, 1956). This quantity of semen deposited into the uterus during natural mating is generally sufficient to establish a sperm reservoir in which enough spermatozoa persist throughout oestrus to ensure high fertility. The fertilization rate of eggs recovered from pigs mated on the 1st or 2nd day of oestrus was found to be similar (Hancock, 1958).

During the early development of practical techniques for A.I. in the pig, numerous experiments were carried out to determine the optimal volume of semen and number of spermatozoa inseminated which might be compatible with high fertility. However, there have been relatively few experiments in which the effects of different volumes of semen, sperm number or sperm concentration on the fertilization of eggs have been systematically examined. Thibault (1959) concluded that the proportion of eggs fertilized was below $100 \%$ when pigs were inseminated with less than $9 \times 10^{9}$ spermatozoa. It was also noted that there were always fewer spermatozoa in the zona pellucida of eggs recovered from artificially inseminated pigs than in eggs recovered from naturally mated animals. The numbers of accessory spermatozoa in the zona pellucida provide some indication of the sperm population within the oviducts when eggs are recovered at specific intervals after ovulation. Hancock \& Hovell (1961) developed a technique of intrauterine insemination by means of a fine catheter introduced via the cervical canal and examined eggs recovered from pigs inseminated with either 20 or $120 \mathrm{ml}$ of diluted semen containing 10,1 or $0.1 \times 10^{9}$ spermatozoa. The fertilization rate of eggs was similar in animals inseminated with 10 or $1 \times 10^{9}$ spermatozoa, but was reduced when only $0.1 \times 10^{9}$ spermatozoa were used. The fertilization rate was also better in animals inseminated with $20 \mathrm{ml}$ rather than $120 \mathrm{ml}$ semen. These results were interesting in that they provided evidence that a very large volume of semen within the uterus was not necessarily required for adequate sperm transport. They also suggested that the efficiency of fertilization might be related not only to the total number of spermatozoa inseminated, but also to the concentration of spermatozoa within the inseminate. A similar conclusion about the effect of sperm concentration on fertilization was reached by Baker, Dziuk \& Norton (1969), although they used a cruder method of intra-cervical insemination and fertilization was negligible following insemination of only $20 \mathrm{ml}$ of diluted semen. Baker et al. (1969) proposed, therefore, that the volume of semen inseminated affects the proportion of pigs in which some spermatozoa reach the site of fertilization, but that the number of spermatozoa reaching the oviducts is dependent on the concentration of spermatozoa in the inseminate. It was suggested that the concentration of spermatozoa should be greater than $10 \times 10^{6} / \mathrm{ml}$ to achieve optimal fertility. Although such critical experiments have not been carried out in horses, it has clearly been established that high fertility can be obtained in mares inseminated with a small volume $(1.5 \mathrm{ml})$ of semen of high sperm density (Pickett \& Voss, 1975). 
The effect of the number of spermatozna inseminated on fertilization has so far been examined only in pigs inseminated at one time relative to ovulation. An attempt to define more precisely the effect on fertilization of different numbers of spermatozoa introduced into the tip of the uterine horn or into the oviduct at various times before ovulation has been made in Cambridge and some details of this experiment are given below.

\section{Fertilization in pigs}

The time of ovulation in gilts was controlled precisely by oral administration of $100 \mathrm{mg}$ methallibure (I.C.I.) per pig per day for 18 days followed by injections of 1000 i.u. PMSG and 500 i.u. hCG 24 and $96 \mathrm{~h}$ later respectively (Polge, Day \& Groves, 1968). A technique of surgical insemination was used which was similar to that described by Polge, Salmon \& Wilmut (1970) and the semen was introduced either into the tip of the uterine horn, close to the uterotubal junction, or directly into the isthmus of the oviduct. Sperm-rich fractions of semen were diluted with homologous seminal plasma and the insemination dose of $0 \cdot 1 \mathrm{ml}$ contained $10^{8}, 10^{7}, 10^{6}, 10^{5}$ or $10^{4}$ spermatozoa. Each gilt received two different insemination treatments, one in each side of the tract (i.e. uterine versus tubal with different sperm numbers) in order to minimize the effect of variation between animals, and inseminations were carried out at 30,18 or $6 \mathrm{~h}$ before ovulation. The time of ovulation was estimated to be $42 \mathrm{~h}$ after hCG injection. The 80 animals involved were killed $14-38 \mathrm{~h}$ after ovulation and the eggs recovered from the reproductive tracts were fixed and stained as whole mounts and examined for evidence of fertilization.

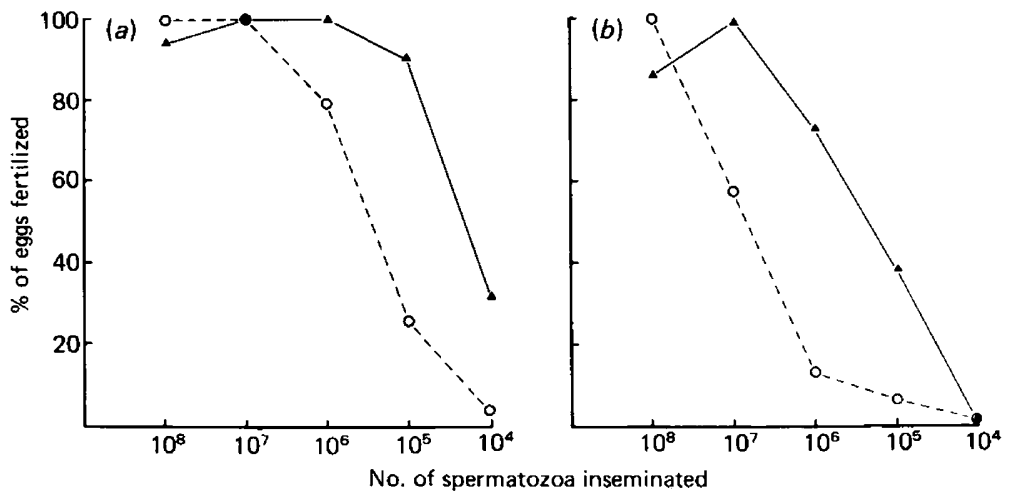

Text-fig. 1. The effect of the number of spermatozoa and site of insemination ( $\Delta$, oviduct; o, uterus) on fertilization in the pig when insemination is effected (a) $6 \mathrm{~h}$ or (b) $30 \mathrm{~h}$ before ovulation.

A comparison of the results obtained in gilts inseminated at $6 \mathrm{~h}$ before ovulation and at $30 \mathrm{~h}$ before ovulation is given in Text-fig. 1. All the eggs were fertilized following tubal insemination of $10^{6}$ spermatozoa or uterine insemination of $10^{7}$ spermatozoa at $6 \mathrm{~h}$ before ovulation, but when the gilts were inseminated $30 \mathrm{~h}$ before ovulation, $100 \%$ fertilization of the eggs was not achieved unless $10^{7}$ spermatozoa were introduced into the oviduct or $10^{8}$ spermatozoa were introduced into the tip of the uterine horn. There was a progressive decrease in the proportion of eggs fertilized as the number of spermatozoa inseminated at either site was reduced. These results obtained by surgical insemination cannot be compared directly with situations in which spermatozoa have been transported throughout the entire reproductive tract. For example, when $10^{6}$ spermatozoa were introduced into the oviduct $6 \mathrm{~h}$ before ovulation, about $20 \%$ of the eggs were penetrated by more than one spermatozoon. Since this is a much higher incidence of polyspermy than would occur following mating or conventional insemination at this time, it is unlikely that as many spermatozoa as this would normally enter the tube. However, the incidence of polyspermy following the introduction of $10^{5}$ spermatozoa into the tube was only $4 \%$. These results, therefore, do provide evidence of a relationship between the sperm numbers required in the uterus and in the isthmus to effect fertilization. They also provide an indication of the survival of spermatozoa within the tract. The insemination dose used in routine A.I. is $50 \mathrm{ml}$ containing $10^{9}$ spermatozoa and pigs are inseminated twice during oestrus. 
PLATE I
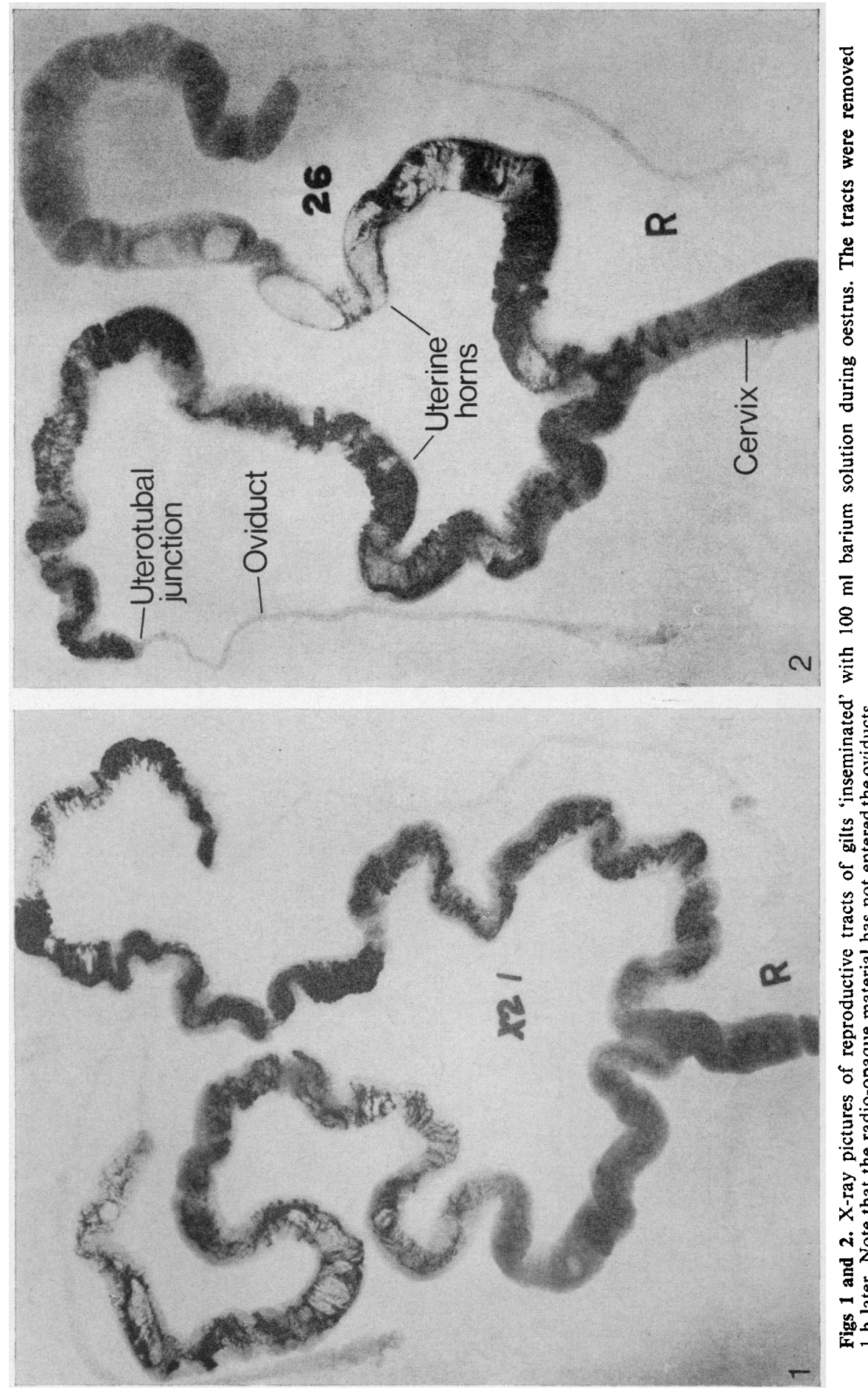

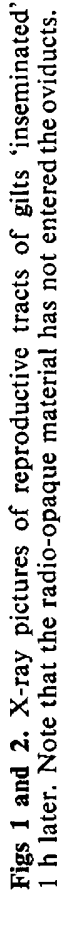


If approximately $10^{7}$ spermatozoa are required at the tip of the uterine horn to produce maximum fertilization in pigs inseminated $6 \mathrm{~h}$ before ovulation, then about $1 \%$ of the insemination dose should reach that region in each horn and the results of A.I. indicate that this is feasible. By contrast, if pigs are inseminated at much longer intervals before ovulation, the efficiency of sperm transport would have to be increased perhaps by an order of 10 and this seems an unlikely achievement. Fertilization rate in pigs inseminated during the early part of oestrus could be improved by increasing the sperm density of the insemination dose. A better alternative, however, is to try to ensure that pigs are inseminated closer to the time of ovulation by inseminating more frequently with fewer spermatozoa as this is less wasteful of semen. There is no doubt that the practice of inseminating pigs twice during oestrus has been one of the main factors in improving the results achieved with A.I.

Some idea of the maximum efficiency that might be expected from A.I. can be obtained from the results of relatively large numbers of inseminations carried out routinely at Cambridge to recover fertilized eggs for various experiments. Pigs were tested daily with a vasectomized boar and during 1976388 gilts were inseminated either on the 2 nd day of oestrus or $24 \mathrm{~h}$ after the injection of hCG with $80-100 \mathrm{ml}$ fresh undiluted semen. The eggs were recovered and examined 1 or 2 days after ovulation. The proportion of animals in which some fertilized eggs were obtained was $85 \%$ and in these animals the proportion of eggs fertilized was $95 \%$. It is possible that the results might have been even higher if sows rather than gilts had been used. Nevertheless, it is questionable whether the very high fertilization rates recorded in some of the experiments with natural mating can in fact be realized when using A.I. on a larger scale. The fertilization rate of eggs in individual animals was as high as could be expected, but the proportion of animals in which no fertilization occurred suggests that it is difficult to ensure by means of A.I. that the semen is introduced and transported adequately in all animals.

Although sperm transport and survival are the main factors influencing fertility in pigs inseminated some time before ovulation, the results of insemination late in oestrus, very close to or after ovulation, will be influenced also by the time required for capacitation of the spermatozoa and the fertilizable life of the eggs. Early experiments at Cambridge in which semen was introduced into the oviducts of pigs shortly after ovulation suggested that a period of 5-6h was required for capacitation of the spermatozoa. By contrast, it was shown that eggs could be penetrated within $3 \mathrm{~h}$ of mating or intra-cervical insemination of pigs close to the time of ovulation (Hunter \& Dziuk, 1968). Later experiments (Hunter \& Hall, 1974b) demonstrated conclusively that direct introduction of spermatozoa and seminal plasma into the oviducts increased the time required for capacitation compared to that needed when semen was placed within the uterus. Both transport of spermatozoa to the site of fertilization and capacitation may therefore be achieved within a relatively short time and a high fertilization rate of eggs can be obtained by mating or insemination close to the time of ovulation. However, if insemination is delayed until only a few hours after ovulation, fertility declines very sharply. Examination of eggs recovered from pigs inseminated at various intervals after ovulation (Hunter, 1967b) has shown that the decline in fertility is due to two reasons. First, in pigs inseminated more than $6 \mathrm{~h}$ after ovulation, the efficiency of sperm transport is diminished and the proportion of animals in which none of the eggs is fertilized is increased. There is also an increased incidence of unilateral fertilization after which fertilized eggs can be recovered from one side of the tract only. (An example of uneven distribution of fluid between the uterine horns is shown in Pl. 1, Fig. 2.) The second and equally important corollary to delayed insemination is that the incidence of polyspermic fertilization rises sharply in animals inseminated more than $6 \mathrm{~h}$ after ovulation. Digyny has also been noted as an abnormality in ageing eggs (Thibault, 1959), but polyspermy occurs more frequently (Hancock, 1959; Hunter, 1967b). It can be estimated, therefore, that the chances of eggs being fertilized and developing normally are high if they are penetrated by spermatozoa within $9-10 \mathrm{~h}$ of ovulation. The actual fertilizable life of the eggs, as measured by their penetrability by spermatozoa, is obviously much longer, but the quality of fertilization and early embryonic development declines.

\section{Preservation of spermatozoa in vitro}

The practical application of A.I. depends to a large extent on the development of effective methods for the preservation of spermatozoa in vitro. The fertilizing capacity of the spermatozoa of several 
species has been prolonged by storage at temperatures slightly above $0^{\circ} \mathrm{C}$. Boar semen, however, is particularly sensitive to cooling and temperatures below $15^{\circ} \mathrm{C}$ cause a progressive and irreversible loss of motility when the spermatozoa are cooled in the presence of seminal plasma (Polge, 1956, 1959). This sensitivity to cooling can be overcome to a large extent by reducing the proportion of seminal plasma present, e.g. by using the sperm-rich fraction of the semen (Ito, Niwa, Kudo \& Mizuho, 1948) or by incubating the semen at about $20^{\circ} \mathrm{C}$ for several hours before cooling (Pursel, Johnson \& Schulman, 1972, 1973a). Egg yolk or milk provide some added protection to the spermatozoa during cooling, but more specific agents such as phosphatidylserine (Butler \& Roberts, 1975) are particularly effective in preserving sperm integrity and motility. Nevertheless, in the routine practice of A.I. in pigs the semen is generally stored at $15-20^{\circ} \mathrm{C}$. A diluent used very widely in Britain and elsewhere for many years has been the so-called IVT diluent (VanDemark \& Sharma, 1957) as modified by du Mesnil du Buisson \& Dauzier (1958) and gassed with $\mathrm{CO}_{2}$. The fertility and litter size in pigs inseminated with semen stored in this medium for 2-3 days have been shown to be similar to that obtained with fresh semen (du Mesnil du Buisson \& Dauzier, 1958; Bennett \& O'Hagan, 1964.) It is possible that the fertilizing capacity of the spermatozoa can be maintained for a little longer in some other diluents (Pursel et al., 1973b) and a medium containing EDTA, as first described by Plisko (1965), is now being used in several countries. Storage for 3-4 days is probably the limit to which the semen can be kept without incurring a drop in fertilizing capacity, but this period, is sufficiently long to permit the operation of an efficient A.I. service.

One of the major problems in the development of A.I. in pigs has been related to the use of frozen semen. Early experiments in which boar semen had been frozen and thawed by techniques similar to those used successfully for the preservation of bull semen gave no fertilization when the semen was used for A.I., despite the fact that a reasonable proportion of the spermatozoa regained motility after freezing and thawing (Polge, 1956, 1959). Today, acceptable levels of fertility can be achieved with frozen-thawed boar semen, but there are still some problems to be overcome, particularly as regards differences in fertility between boars, before low-temperature preservation can be considered a generally reliable technique.

Some of the steps in the evolution of the methods now used for freezing and thawing boar spermatozoa are interesting in that they have introduced some new ideas about the factors affecting the fertilizing capacity of spermatozoa. It was established some time ago that glycerol adversely affected boar spermatozoa (Polge, 1956) and exposure of the spermatozoa at ambient temperatures to glycerol concentrations of $5 \%$ or more caused a significant reduction in fertilizing capacity (Graham, Rajamannan, Schmehl, Maki-Laurila \& Bower, 1971; Wilmut \& Polge, 1974). Although there was no obvious change in the motility or morphology of the spermatozoa, increased leakage of some enzymes caused by the addition of glycerol suggested that membrane damage was involved (Graham et al., 1971). On the other hand, the recovery of motility of the spermatozoa after freezing and thawing was generally reduced when the concentration of glycerol in the diluent was much below $5 \%$ (Salamon, Wilmut \& Polge, 1973; Wilmut, Salamon \& Polge, 1973).

The first clue to the effect of glycerol on the fertilizing capacity of the spermatozoa was obtained by means of surgical insemination (Polge et al., 1970). When spermatozoa which had been frozen in the presence of 3-5\% glycerol were introduced directly into the oviducts, fertilization of all the eggs was achieved. By contrast, fertilization was negligible when semen treated in a similar way was placed at the tip of the uterine horn, even when very large numbers of spermatozoa were used. These observations suggested that the depressive effect of glycerol on fertilizing capacity only became evident when the spermatozoa were placed within the uterine environment. It appeared that the spermatozoa were not surviving at the uterotubal junction and too few were able to reach the site of fertilization, If, therefore, fertility was to be obtained with frozen semen inseminated via the cervix, lower concentrations of glycerol would presumably have to be used despite the fact that fewer spermatozoa might survive freezing and thawing. This concept proved to be true and in experiments in which the spermatozoa were frozen in various concentrations of glycerol and inseminated into the tip of the uterine horn or into the uterus via the cervix, maximum fertilization was obtained with semen frozen in the presence of only $2 \%$ glycerol (Wilmut \& Polge, 1972). Experiments in other 
laboratories at the same time led to very similar conclusions. Fertilization in pigs inseminated via the cervix was obtained with spermatozoa which had been frozen and thawed in several different media (Graham et al., 1971; Pursel \& Johnson, 1971; Crabo \& Einarsson, 1971). In all methods, however, glycerol was either omitted entirely or included only in very low concentration in the diluted semen.

Laboratory assessment of the potential fertilizing capacity of boar spermatozoa after freezing and thawing has been particularly difficult. Certainly motility per se is a very poor criterion when related to spermatozoa in the presence of glycerol. Sperm morphology, especially changes induced in the acrosome, may be more useful as it has been shown that there is a progressive increase in the proportion of spermatozoa with damaged acrosomes when they are frozen and thawed in increasing concentrations of glycerol or other permeating cryoprotective agents. By contrast, acrosomal damage is relatively small when the spermatozoa are frozen and thawed in media containing only sugars and egg yolk, although the survival of motility is poorer (Graham et al., 1971; Wilmut \& Polge, 1977a). The loss of enzymes after thawing is also greater in the presence of glycerol (Graham et al., 1971). By combining a number of laboratory tests, but particularly by direct experiments on the fertilizing capacity of the spermatozoa following A.I., various improvements in the methods of low temperature preservation have been developed. These include the use of sperm-rich fractions and equilibration before cooling, diluting media which are low in electrolyte concentration but in which the osmotic pressure is maintained by sugars and/or organic buffers, and the addition of only very low glycerol concentrations (Graham et al., 1971; Pursel \& Johnson, 1971; Salamon et al., 1973). In diluents containing egg yolk, the inclusion of a surfactant, Orvus, has also been claimed to be beneficial (Graham et al., 1971; Pursel \& Johnson, 1975). The semen is generally frozen by the pellet method (Nagase \& Niwa, 1964). In early experiments the pellets were thawed by sprinkling them on a warm surface, but thawing them in a diluent has given better results (Richter \& Leidicke, 1972; Pursel \& Johnson, 1975). Some early success was obtained by thawing the pellets in seminal plasma (Crabo \& Einarsson, 1971) and the composition of the thawing medium has been shown to affect sperm survival and fertility (Larsson \& Einarsson, 1976; Paquignon, Dacheux \& Courot, 1977).

The results of some of the experiments with frozen semen undertaken at Cambridge during recent years illustrate the fertilization rates that can be achieved with semen treated in a number of different ways (Polge, 1976). A total of 532 gilts was inseminated and the eggs were recovered from all animals within 1 or 2 days of ovulation. The overall proportion of gilts fertilized was $75 \%$ and the average proportion of eggs fertilized in these gilts was $70 \%$. There was no difference in fertility between semen frozen in a simple egg yolk-glucose medium (Polge et al., 1970) or in the BF5 medium described by Pursel \& Johnson (1975). Equivalent results were obtained following insemination of semen frozen in diluents containing 0 or $1 \%$ glycerol, but fertility was depressed when the concentration of glycerol was above $2 \%$. The total number of spermatozoa used per insemination in the majority of experiments was $2.5 \times 10^{9}$ in a volume of $50 \mathrm{ml}$ and the gilts were inseminated twice during the 2 nd day of oestrus. Additional experiments, however, have shown that equally good results can be obtained with the semen of some boars if the number of spermatozoa inseminated is no greater than that used for routine insemination of fresh semen (Table 1). By contrast, differences in fertility between boars were noted (Table 2) although these differences in fertilizing capacity could not be correlated with sperm motility or morphology after thawing. A possible explanation for some of the differences in fertility between boars has been obtained by examining the effect of including extra seminal plasma in the semen to be frozen. The semen of 2 boars was collected in fractions and half of the sperm-rich fraction of each was diluted $1: 10$ with homologous seminal plasma. It was then equilibrated, diluted and frozen in the presence or absence of the added seminal plasma. In one boar there was a very marked effect of seminal plasma on the fertilizing capacity of the spermatozoa, whereas in the other there was no effect (Table 3).

In none of the experiments with frozen semen has the proportion of fertilized eggs been as high as that obtained with fresh semen. Similarly, when the proportion of fertilized eggs recovered has been low, the number of accessory spermatozoa found within the zona pellucida of the eggs has also been very low and this indicates that there is only a small population of viable spermatozoa at the site of 
Table 1. Fertility in gilts inseminated (a.m. and p.m. on 2 nd day of oestrus) with low numbers of frozen-thawed spermatozoa (one ejaculate from each of 4 boars)

\begin{tabular}{cccc}
\hline $\begin{array}{c}\text { No. of sperm } \\
\text { per dose }\end{array}$ & $\begin{array}{c}\text { No. of gilts } \\
\text { inseminated }\end{array}$ & $\begin{array}{c}\text { No. (\%) of gilts } \\
\text { fertilized }\end{array}$ & $\begin{array}{c}\% \text { eggs fertilized in gilts } \\
\text { with fertilized eggs }\end{array}$ \\
\hline $2 \times 10^{9}$ & 23 & $17(74)$ & 89 \\
$1 \times 10^{9}$ & 24 & $15(63)$ & 73 \\
\hline
\end{tabular}

Table 2. Difference in fertilizing capacity of frozen-thawed semen between two groups of boars

\begin{tabular}{cccccc}
\hline Group & No. of boars & $\begin{array}{c}\text { No. of sperm } \\
\text { per dose } \\
\left(\times 10^{9}\right)\end{array}$ & $\begin{array}{c}\text { No. of gilts } \\
\text { inseminated* }\end{array}$ & $\begin{array}{c}\text { No. (\%) of gilts } \\
\text { fertilized }\end{array}$ & $\begin{array}{c}\% \text { eggs fertilized in gilts } \\
\text { with fertilized eggs }\end{array}$ \\
\hline High fertility & 5 & 2.5 & 20 & $20(100)$ & 87 \\
Low fertility & 4 & $5 \cdot 0$ & 19 & $18(96)$ & 84 \\
& & 2.5 & 15 & $5(38)$ & 30 \\
& 5.0 & 16 & $11(69)$ & 80 \\
\hline
\end{tabular}

* a.m. and p.m. on 2 nd day of oestrus.

Table 3. Effect of freezing boar spermatozoa in the presence of seminal plasma

\begin{tabular}{clccc}
\hline Boar & \multicolumn{1}{c}{ Type of semen frozen } & $\begin{array}{c}\text { No. of gilts } \\
\text { inseminated* }\end{array}$ & $\begin{array}{c}\text { No. of gilts } \\
\text { fertilized }\end{array}$ & $\begin{array}{c}\% \text { eggs fertilized in gilts } \\
\text { with fertilized eggs }\end{array}$ \\
\hline \multirow{2}{*}{ A } & Sperm-rich fraction & 10 & 10 & 96 \\
& Sperm-rich fraction + seminal plasma & 10 & 1 & 56 \\
B & Sperm-rich fraction & 10 & 8 & 74 \\
& Sperm-rich fraction + seminal plasma & 10 & 8 & 64 \\
\hline
\end{tabular}

* With $2.5 \times 10^{9}$ spermatozoa per dose, a.m. and p.m. on 2 nd day of oestrus.

fertilization. It was suggested by Wilmut \& Polge (1977b) that perhaps the uterotubal junction selects against the survival and transport of frozen and thawed spermatozoa with damaged membranes. This explanation is supported by evidence that the ratio of the number of spermatozoa required to give fertilization when the semen is placed at the tip of the uterine horn or in the oviduct is very different when inseminating frozen (Polge et al., 1970) or fresh spermatozoa. The survival of spermatozoa in the uterine environment may therefore be affected by changes at the sperm surface induced by freezing and thawing and these changes may be related to factors present in the seminal plasma. A similar explanation was put forward by Pavelko \& Crabo (1976) and they noted a marked reduction in sperm coating proteins during freezing and thawing. Differences in fertilizing capacity of frozen-thawed spermatozoa from different males has also been conclusively demonstrated with bull semen by means of competitive fertilization experiments (Beatty, Stewart, Spooner \& Hancock, 1976). In cattle A.I., however, the semen is usually inseminated directly into the uterus (i.e. beyond the cervix which constitutes the normal barrier to sperm transport in the cow) and therefore variations in fertility between males may be less evident.

Experiments with frozen stallion semen have been far less extensive than those with boar semen, but problems of reduced fertility, particularly with the semen of some stallions (Pace \& Sullivan, 1975) appear to be very similar. Removal of seminal plasma before freezing (Nishikawa, 1975) or the 
use of sperm-rich fractions of semen (Merkt, Klug, Krause \& Bader, 1975) improves the recovery of spermatozoa after freezing and thawing and in these studies the fertility of the frozen-thawed spermatozoa was good.

In all species, further experiments on the preservation of spermatozoa will undoubtedly be aided by studies on factors affecting the transport and survival of spermatozoa in different regions of the female reproductive tract and by direct observations on the fertililization of eggs.

\section{References}

Austin, C.R. (1964) Behaviour of spermatozoa in the female genital tract and in fertilization. Proc. 5th Int. Congr. Anim. Reprod. \& A.I., Trento 3, 7-22.

Baker, R.D., Dziuk, P.J. \& Norton, H.W. (1968) Effect of volume of semen, number of sperm and drugs on transport of sperm in artificially inseminated gilts. J. Anim. Sci. 27, 88-93.

Beatty, R.A., Stewart, D.L., Spooner, R.L. \& HANCOCK, J.L. (1976) Evaluation by the heterospermic insemination technique of the differential effect of freezing at $-196^{\circ} \mathrm{C}$ on fertility of individual bull semen.J. Reprod. Fert. 47, 377-379.

BennetT, G.H. \& O'Hagan, C. (1964) Factors influencing the success of artificial insemination of pigs. Proc. 5th Int. Congr. Anim. Reprod. \& A.I., Trento 3, 481-487.

Butler, W.J. \& Roberts, T.K. (1975) Effects of some phosphatidyl compounds on boar spermatozoa following cold shock or slow cooling. J. Reprod. Fert. 43, 183-187.

Crabo, B. \& Einarsson, S. (1971) Fertility of deep frozen boar spermatozoa. Acta vet. scand. 12, 125127.

DAY, F.T. (1942) Survival of spermatozoa in the genital tract of the mare.J.agric. Sci, 32, 108-111.

du Mesnil du Buisson, F. \& Dauzier, L. (1955) La remontée des spermatozoides du verrat dans le tractus génitale de la truie en oestrus. C. r. Séanc. Soc. Biol. 149, 76-79.

du MESnil du Buisson, F. \& Dauzier, L. (1958) Maintien du pouvoir fécondant du sperme de verrat en présence de gaz carbonique. C. r. hebd. Séanc. Acad. Sci., Paris D 247, 2472-2475.

Dziuk, P.J., Polge, C. \& Rowson, L.E.A. (1964) Intrauterine migration and mixing of embryos in swine following egg transfer. J. Anim. Sci. 23, 37-42.

Graham, E.F., Rajamannan, A.H.S., SchmehL, M.K.L. Makilaurila, M. \& Bower, R.E. (1971) Preliminary report on procedure and rationale for freezing boar semen. A.I. Digest 19, 12-14.

HANCock, J.L. (1958) The fertility of natural and of artificial matings in the pig. Stud. Fert. 9, 146-158.

Hancock, J.L. (1959) Polyspermy of pig ova. Anim. Prod. 1, 103-106.

HANCOCK, J.L. \& Hovell, G.J.R. (1961) The effect of semen volume and number of spermatozoa on the fertility of intra-uterine inseminations of pigs. Anim. Prod. 3, 153-161.

HunTER, R.H.F. (1967a) Porcine ovulation after injection of human chorionic gonadotrophin. Vet. Rec. 81, 21-23.
HuNTER, R.H.F. (1967b) The effects of delayed insemination on fertilization and early cleavage in the pig.J. Reprod. Fert. 13, 133-147.

HUNTER, R.H.F. (1973) Transport, migration and survival of spermatozoa in the female genital tract: species with intra-uterine deposition of semen. In Sperm Transport, Survival and Fertilizing Ability, pp. 309-342. (Inserm colloquium No. 26.)

Hunter, R.H.F. (1975a) Physiological aspects of sperm transport in the domestic pig, Sus scrofa. 1. Semen deposition and cell transport. $B r$. vet. $J .131$, 565-573.

HưNTER, R.H.F. (1975b) Physiological aspects of sperm transport in the domestic pig, Sus scrofa. II. Regulation, survival and fate of cells. Br. vet. J. 131, 681-689.

Hunter, R.H.F. \& DzIUK, P.J. (1968) Sperm penetration of pig eggs in relation to the timing of ovulation and insemination. J. Reprod. Fert. 15, 199-208.

HuNTER, R.H.F. \& HALL, J.P. (1974a) Capacitation of boar spermatozoa: the influence of post-coital separation of the uterus and Fallopian tubes. Anat. Rec. 180, 597-604.

HunTER, R.H.F. \& Hall, J.P. (1974b) Capacitation of boar spermatozoa: synergism between uterine and tubal environments. $J$. exp. Zool. 188, 203-214.

Ito, S., Niwa, T., Kudo, A. \& Mizuro, A. (1948) Studies on the artificial insemination in swine. Part II. Observations on the semen and its storage trial. Res. Bull. Chiba zootech. Exp. Stn. 55, 17-56.

LARSSON, K. \& EINARsson, S. (1976) Fertiiity of deep frozen boar spermatozoa. Influence of thawing diluents and of boars. Acta. vet. scand. 17, 43-62.

Mann, T., Polge, C. \& Rowson, L.E.A. (1956) Participation of seminal plasma during the passage of spermatozoa in the female reproductive tract of the pig and horse. J. Endocr. 13, 133-140.

MerkT, H., Klug, F., Krause, D. \& Bader, H. (1975) Results of long-term storage of stallion semen frozen by the pellet method. J. Reprod. Fert., Suppl. 23, 105106.

Nagase, H. \& Niwa, T. (1964) Deep freezing bull semen in concentrated pellet form. I. Factors affecting survival of spermatozoa. Proc. 5th Int. Congr. Anim. Reprod. \& A.I., Trento 3, 410-425.

Nishikawa, Y. (1975) Studies on the preservation of raw and frozen horse semen. J. Reprod. Fert., Suppl. 23, 99-104.

PaCe, M.M. \& Sullivan, J.J. (1975) Effect of timing of insemination, numbers of spermatozoa and extender components on the pregnancy rate in mares insemiDownloaded from Bioscientifica.com at 04/26/2023 10:00:41AM via free access 
nated with frozen stallion semen. J. Reprod. Fert., Suppl.23, 115-121.

PaQtignon, M., Dacheux, J.L. \& Courot, M. (1977) Effect de differentes solutions de decongelation sur le pouvoir fécondant des spermatozoides de verrat. Journées de la Recherche porcine en France (1977), $15-18$.

Parker, W.G., Sullivan, J.J. \& First, N.L. (1975) Sperm transport and distribution in the mare. $J$. Reprod. Fert., Suppl. 23, 63-66.

Pavel Ko, M.K. \& CRabo, B.G. (1976) Possible importance of some sperm coating proteins and their behaviour during preservation of boar spermatozoa. Proc. 8th Int. Congr. Anim. Reprod. \& A.I., Krakow 4, 1045-1048.

Perry, J.S. (1960) The incidence of embryonic mortality as a characteristic of the individual sow. $J$. Reprod. Fert. 1, 71-83.

PERRY, J.S. \& Rowlands, I.W. (1962) Early pregnancy in the pig.I. Reprod. Fert. 4, 175-188.

Picketr, B.W. \& Voss, J.L. (1972) Reproductive management of the stallion. Proc. 18th Ann. Conv. Am. Ass. equine Pract. pp. 501-531.

PICKETT, B.W. \& Voss, J.L. (1975) The effect of semen extenders and sperm number on mare fertility. $J$. Reprod. Fert., Suppl.23, 95-98.

Plisko, N.T. (1965) [A method for prolonging the viability and fertilizing ability of boar spermatozoa.] Svinovodstvo 19, 37-41. Anim. Breed. Abstr. 89, 508.

Polge, C. (1956) Artificial insemination in pigs. Vet. Rec. 68, 62-76.

Polge, C. (1959) Some experiments on the preservation of boar semen. Annls Zootech. 8, Suppl. 113-120.

Polge, C. (1976) The fertilizing capacity of boar spermatozoa following freezing and thawing, Proc. 8th Int. Congr. Anim. Reprod. \& A.I., Krakow 4, 10611064.

Polge, C., Day, B.N. \& Groves, T.W. (1968) Synchronization of ovulation and artificial insemination in pigs. Vet. Rec. 83, 136-142.

Polge, C., Salamon, S. \& Wilmut, I. (1970) Fertilizing capacity of frozen boar semen following surgical insemination. Vet. Rec. 87, 424-428.

PURSel, V.G. \& Johnson, L.A. (1971) Fertility with frozen boar spermatozoa. J. Anim. Sci. 33, 265.

PURsel, V.G. \& JoHnson, L.A. (1975) Freezing of boar spermatozoa: fertilizing capacity with concentrated semen and a new thawing procedure. J. Anim. Sci. 40,99-102.

PURSEL, V.G., Johnson, L.A. \& SChULman, L.L. (1972) Interaction of extender composition and incubation period on cold shock susceptibility of boar spermatozoa.J. Anim. Sci. 35, 580-584.

PuRSEL, V.G., Johnson, L.A. \& SCHULMAN, L.I.. (1973a) Effect of dilution, seminal plasma and incubation period on cold shock susceptibility of boar spermatozoa.J. Anim. Sci.37, 528-531.
Pursel, V.G., Johnson, L.A. \& Schulman, L.L. (1973b) Fertilizing capacity of boar semen stored at $15^{\circ} \mathrm{C}$. J. Anim. Sci. 37, 532-535.

Richter, L. \& LeIdicke, A. (1972) Fin verfahren zam tiefogefrieren von ebersperm. Proc. 7 th Int. Congr. Anim. Reprod. \& A.I., Munich 2, 1617-1621.

RIGBY, J.P. (1964) The fate of spermatozoa in the genital tract of the sow following artificial insemination. Proc. Sth Int. Congr. Anim. Reprod. \& A.I., Trento 4, 421-425.

RIGBY, J.P. (1966) The persistance of spermatozoa at the uterotubal junction of the sow. J. Reprod. Fert. 11, 153-155.

Rowson, L.E.A. (1955) The movement of radio opaque material in the bovine uterine tract. Br. vet. J. 111, 334-342.

Salamon, S., Wilmut, I. \& Polge, C. (1973) Deep freezing of boar semen. I. Effects of diluent composition, protective agents and method of thawing on survival of spermatozoa. Aust. J. biol. Sci. 26, 219230.

Sullivan, J.J., Turner, P.C., Self, L.C., GutTeridge, H.B. \& BarTlETT, D.E. (1975) Survey of reproductive efficiency in the Quarter-horse and Thoroughbred.J. Reprod. Fert., Suppl.23, 315-318.

Thibault, C. (1959) Analyse de la fécondation de l'oeuf de la truie après accouplement ou insémination artificielle. Annls Zootech 8, Suppl., 165-177.

VanDemark, N.L. \& Sharma, V.D. (1957) Preliminary fertility results from the preservation of bovine semen at room temperature. J. Diary Sci., 40, 438439.

Wilmut, I. \& Polge, C. (1972) The freezing of boar spermatozoa. Proc. 7th Int. Congr. Anim. Reprod. \& A.I., Munich 2, 1611-1615.

WILMUT, I. \& PoLge, C. (1974) The fertilizing capacity of boar semen stored in the presence of glycerol at 20 , 5 and $-79^{\circ} \mathrm{C}$. J. Reprod. Fert. 38, 105-113.

Wilmut, I. \& Polge, C. (1977a) The low temperature preservation of boar spermatozoa. I. The motility and morphology of boar spermatozoa frozen and thawed in the presence of permeating protective agents. Cryobiology 14, 471-478.

WiLmut, I. \& Polge, C. (1977b) The low temperature preservation of boar spermatozoa. 3. The fertilizing capacity of frozen and thawed boar semen. Cryobiology 14, 483-491.

Wilmut, I., Salamon, S. \& Polge, C. (1973) Deep freezing of boar semen. II. Effects of method of dilution, glycerol concentration and time of semenglycerol contact on survival of spermatozoa. Aust.J. biol. Sci. 231-237.

Wrathall, A.E. (1971) Prenatal survival in pigs. Pt. 1. Ovulation rate and its influence on prenatal survival and litter size in pigs. Review Series Commw. Bur. Anim. Hlth. No. 9. 